\title{
Coupling Coordination Analysis of Urban Tourism Environment Quality and the Tourism Economy: A Case Study of Nanjing City
}

\author{
Hongmei Guan $\mathbb{i D}^{1}$ and Xin Guo $\mathbb{i}^{2}$ \\ ${ }^{1}$ Business School, Hohai University, Nanjing 211106, China \\ ${ }^{2}$ College of Economics and Management, Nanjing University of Aeronautics and Astronautics, Nanjing 211106, China
}

Correspondence should be addressed to Hongmei Guan; ghm8670302@163.com

Received 29 July 2021; Revised 28 December 2021; Accepted 25 January 2022; Published 21 February 2022

Academic Editor: Jianguo Wang

Copyright (c) 2022 Hongmei Guan and Xin Guo. This is an open access article distributed under the Creative Commons Attribution License, which permits unrestricted use, distribution, and reproduction in any medium, provided the original work is properly cited.

\begin{abstract}
There is a complex interaction between the quality of the urban tourism environment and the tourism economy. The former is the key to sustainable development of the tourism economy, which, in turn, also has an impact on the urban tourism environment. Therefore, understanding the coupling coordination relationship between them is crucial. This paper aims to construct a comprehensive evaluation index system of urban tourism environment quality system and the tourism economic system and adopts the entropy method to weigh the indexes. The comprehensive evaluation model and coupling coordination degree model are exploited to conduct an empirical analysis of the changes in Nanjing's tourism environment quality, tourism economy comprehensive development level, and coupling coordination degree from 2009 to 2020. The results show that the coupling coordination degree shows a fluctuating upward trend overall. In particular, the traffic environment and tourism benefits have the most significant impact on the coupling system, indicating that relevant departments need to consider these key factors when making macrodecisions.
\end{abstract}

\section{Introduction}

The tourism industry has become a strategic pillar industry in China and an important driving force to promote highquality development of the regional economy and industrial structure [1]. According to a report released by the Ministry of Culture and Tourism, the total tourism revenue in 2018 was 5.97 trillion yuan, and the comprehensive contribution of the national tourism industry to GDP in 2018 was as high as 9.94 trillion yuan, accounting for $11.04 \%$ of the total GDP. Notably, cities are the most important tourist destinations and the supporting points of modern tourism in China. Furthermore, urban tourism can also accelerate the development of the regional economy and transportation networks. High-quality ecological environment, urban services, and infrastructure are crucial factors for the smooth development of urban tourism and important indicators for evaluating the quality of the urban tourism environment. Besides, the development of the tourism industry can boost the continuous improvement of ecological environment, tourism infrastructure, and transportation facilities. However, the rapid development of urban tourism causes environmental pollution and ecological damage: $70 \%-75 \%$ of the global energy consumption and $80 \%$ of carbon dioxide emissions come from urban areas, where air pollution, water pollution, traffic jams, and overcrowding also occur [2]. In 2016, the Chinese government proposed green development to enhance the value of tourism ecological development, implement green tourism, and strengthen tourism environmental protection. However, it is still unknown whether the ecological environment, tourism infrastructure, and traffic environment of the urban tourism industry will promote the growth of the tourism economy or whether the tourism economy will affect the ecological environment, tourism infrastructure, and traffic facilities. Therefore, how to correctly coordinate the relationship between urban tourism environment quality and tourism economy is a challenging and important task, which has become the key to 
realizing the sustainable development of urban tourism, and therefore received strong attention from both academic scholars and the industry.

Previous studies have mostly examined the relationship between urban tourism economy and urban tourism environment quality from a single perspective, such as ecological environment and urban economy [3]; urban infrastructure and economy, society, and environment [4]; or traffic environment and tourism development [5]. However, urban tourism environmental quality is complex, and there are few comprehensive studies on it. Currently, there is no set of suitable comprehensive evaluation indexes to measure the coordination relationship between the quality of urban tourism environment and tourism economy, which may hinder the sustainable development of urban tourism. Thus, this study proposes the coupling evaluation index for the urban tourism environment quality and tourism economy systems by taking Nanjing as an example and calculates the index weight and the comprehensive evaluation development level of the system by applying the entropy method and comprehensive development level model, respectively. Then, the coupling coordination degree model is used to quantify the coupling coordination relationship between the urban tourism environment quality and the tourism economy systems. Finally, this paper provides macro suggestions for the two-system coupling coordination development strategy of relevant departments in Nanjing. Therefore, the contribution of this study lies in (1) defining the connotations of tourism environment quality from a more comprehensive and multidimensional perspective, explaining the relationship between urban ecological environment, tourism infrastructure, and traffic environment and tourism economy, and expanding the previous research content; (2) establishing a scientific and objective index evaluation system, including two subsystems, six aspects, and twenty-five indexes, and adopting the objective entropy weight method to weigh the indexes, which can provide a reference for other scholars to establish indicators; (3) revealing the dynamic trend of the coupling and coordinated development of urban tourism environmental quality and tourism economy, breaking through the limitations of traditional research on the interaction between systems; (4) understanding the coupling coordination degree between tourism environmental quality and tourism economy, which is expected to help decision-makers improve management efficiency, provide scientific references for making work plans, and establish a foundation for future research.

\section{Literature Review}

The quality of the tourism environment involves various factors, on which scholars have not reached a consensus so far. In general, the tourism environment refers to a composite system centered on tourism activities, involving tourism destinations and tourism-supporting destinations (but mainly tourism destinations), and composed of the natural ecological environment as well as the cultural and social environment. Therefore, tourism environment quality mainly includes the factors of the ecological environment, tourism infrastructure, and transportation facilities, in this study. Among these, the ecological environment as a factor affecting sustainable development is quite important and has received unprecedented attention in China; tourism infrastructure provides basic material guarantees for the development of urban tourism, and the traffic environment is an important index to measure tourism development. Thus, it can be seen that the ecological environment, tourism infrastructure, and transportation facilities all promote or constrain each other and jointly affect the development of tourism environmental quality. Despite scholars having conducted a large number of empirical studies on the coupling coordination relationship between the quality of urban tourism environment and the development of tourism economy, indicating the importance of academic research on the two, to our knowledge no previous study has focused on the relationship between comprehensive environmental quality and tourism economy. Therefore, it is necessary to construct a comprehensive urban tourism environment quality system to explore the relationship between them.

\subsection{Impact of Urban Tourism Environment Quality on} Tourism Economy. In this study, the quality of the urban tourism environment is viewed from three perspectives, i.e., the ecological environment, tourism infrastructure, and traffic environment, due to its complex nature. Furthermore, many scholars have published a large number of studies on tourism environment quality from different perspectives; e.g., Becken and Patterson [6] pointed out that the environmental quality of tourist destinations is particularly important. Transportation, accommodation, and greenhouse gas emissions have a direct impact on the environment [7]; Tang [8] emphasizes that satisfactory ecological environment is the foundation of tourism development and can even become a unique tourism resource; Alkheder [9] considers that the improvement of transportation network also plays a vital role in the sustainable development of tourism, which is consistent with Lundgren's view [10]. Hence, we believe that it is necessary to improve the tourism environment quality of destinations, based on previous research.

The quality of the urban tourism environment can both promote and hinder the development of tourism economy. Ouattara et al. [11] studied the dynamic interaction between tourism and environmental quality, focusing on the positive impact of tourism environment quality on tourism economic development. Tang [8] stated that the development of tourism depends, to a large extent, on the natural environment, and a good ecological environment can attract more tourists. For instance, the improvement of air quality provides more opportunities for the sustainable development of tourism [12]. Its improvement depends on the supporting environmental infrastructure, the use of clean energy, and the improvement of public transportation services, all of which will promote the sustainable development of tourism. In short, ecological environment is the basis for developing the tourism economy and improving tourism economic benefits [13-15]. In addition, Prideaux 
[16] believes that transportation infrastructure is the main promoting or inhibiting factor for regional tourism economic growth. The improvement of transportation in tourist destinations determines tourism motivation and also has a direct impact on tourist satisfaction [5]. Massidda and Etzo [17] adopted Gaussian Mixture Model (GMM) to verify the boosting effect of transportation infrastructure on the development of the tourism economy. Therefore, a highquality transportation infrastructure is an important guarantee for tourism economic growth and sustainable development. In contrast, air pollution will cause psychological discomfort and negative word-of-mouth among tourists [18], generating negative impact on the tourism industry [19] and leading to a decline in the tourism economy. Goeldner and Ritchie [20] proposed that transportation infrastructure also has a restraining effect on the development of the regional tourism economy.

\subsection{Impact of Tourism Economy on Urban Tourism Envi-} ronment Quality. Tourism economy has positive and negative effects on the quality of urban tourism environment, directly or indirectly. As far as is known, while accelerating economic growth, tourism will emit a large amount of carbon dioxide and affect the regional environment quality [21]. In addition, researchers in developed countries such as Spain and in developing countries such as China have studied the negative impact of tourism on the environment through grounded theory and questionnaires [22, 23]. Sghaier et al. [24] examined the impact of tourism development on economic growth, carbon dioxide emissions, and environmental quality in Tunisia, Egypt, and Morocco. The research results confirm that tourism growth is related to environment quality. Akbostanc1 et al. [25] tested the relationship between economic growth and environmental pollution based on Environment Kuznets Curve (EKC). Shahbaz et al. [26] found an inverted U-shaped relationship between economic growth and $\mathrm{CO}_{2}$ emissions. Based on sustainable development theory, Mbaiwa [27] studied and analyzed the negative impact of tourism industry on the environment in the Okavango Delta in northern Botswana. Tourism development has destroyed the natural and social environment of many destinations [12], including through land use change, excessive energy consumption, the spread of diseases, and the consequent psychological discontent [28]. Among others, air pollution has become the dominant factor contributing to environmental pollution in many cities [29, 30]; PM2.5 and smog are sources of severe environmental pollution in Beijing, Tianjin, and Hebei [31, 32]; and the large increase in the use of vehicles in tourist destinations will also cause serious environmental pollution $[28,33,34]$.

In addition, some scholars have studied the impact of tourism economy on the quality of urban tourism environment from a positive perspective. Gossling et al. [35] believe that tourism has stimulated changes in the air and environment in a positive way and that this, in turn, will also change tourism itself. For instance, every $0.105 \%$ increase in tourism revenue will help reduce carbon dioxide emissions by $1 \%$ [36]. Paramati et al. [37] found that tourism in developed countries results in carbon dioxide emission faster than in developing countries. Wang et al. [14] pointed out that tourism is a new economic growth mode that reduces carbon emissions and increases economic income compared with the secondary industry. Therefore, tourism industry is considered as a low-carbon industry [38], which is conducive to the upgrading of industrial structure [39], the renewal of urban functions, and the protection of the air environment $[40,41]$.

\subsection{The Relationship between Urban Tourism Environment} Quality and Tourism Economy. Coupling refers to the relationship between two or more systems and is mainly used to analyze the coupling degree and coupling coordination degree between different systems or different elements, so as to explore the coupling coordination development between systems [42]. In this study, the interaction between the urban tourism environment quality system and the tourism economic system is complex because the indexes of the two systems change with time [43]. Hence, this method is wellsuited for analyzing the dynamic and complex relationship between the urban tourism environment quality system and the tourism economic system. So far, scholars have adopted this method to investigate the relationship between tourism and environment [8], urbanization and ecological environment [44, 45], urbanization and air environment [13], tourism, transportation, and low-carbon cities [46], and the industrial agglomeration and regional economy [47]. However, there is no research exploiting coupling methods to study the relationship between the comprehensive urban tourism environment quality system and the tourism economic system.

Building on previous studies, this paper establishes the relationship between urban tourism environment quality and tourism economy (Figure 1). As seen in Figure 1, on the one hand, the quality of urban tourism environment provides an important guarantee for the development of tourism economy. It shows that a good ecological environment, high-quality infrastructure, and convenient transportation will undoubtedly increase the number of tourists in the city and expand the scale of tourism consumption, thus driving the development of tourism and injecting new vitality for the development of regional economy. Based on the calculations of the World Tourism Organization (UMWTO), each additional direct employment in the tourism industry contributes to five indirect employment opportunities [48]. In contrast, the influx of tourists will cause more environmental pollution and traffic jams, which will negatively affect the tourism industry and hinder the development of urban tourism. On the other hand, the development of the tourism economy has constantly improved the tourism infrastructure, promoted the development of interregional and intracity traffic, and provided convenience for tourists in many ways. However, tourism will cause damage to the ecological environment at the same time as spurring economic development, such as by the increase of carbon dioxide emissions, the decrease of 


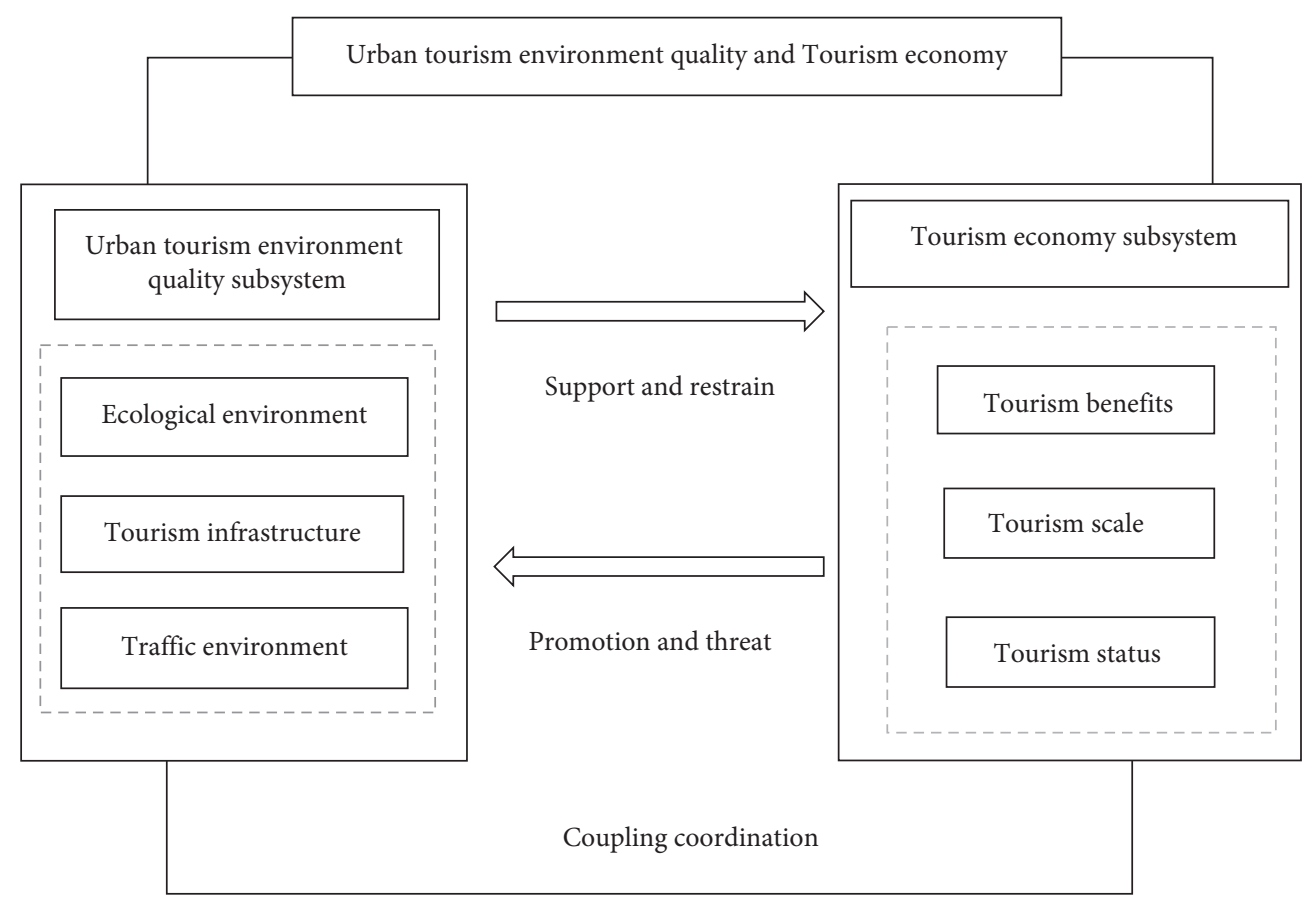

FIgURE 1: The relationship between urban tourism environment quality and the tourism economy.

urban deep forest greening rate, and the decrease of percapita green area. Therefore, tourism environmental quality system and tourism economic system coupling coordination is of priority to promote the sustainable development of urban tourism.

\section{Materials and Methods}

3.1. Study Area. Nanjing is located in eastern China and the middle of the lower reaches of the Yangtze River. It has 11 districts with a total area of 6,587 square kilometers. Nanjing is an important gateway city in the Yangtze River Delta, which is planned and positioned by the State Council and drives the development of the central and western regions. It is also an important node city where the eastern coastal economic belt and the Yangtze River economic belt converge strategically. It has long been the political, economic, and cultural center of southern China and is one of the first batches of national historical and cultural cities. Nanjing possesses rich tourism resources. As of 2018, there were two 5A scenic spots, fifty-three A scenic spots, seventy-six starrated hotels, and seven hundred travel agencies in Nanjing. The rapid economic development and urbanization in Nanjing have brought great pressure to the urban environment; e.g., sulfur dioxide and inhalable particulate matter levels are increasing continuously. The Nanjing Municipal Government has taken decisive intervention measures toward sustainable development of the ecological environment. In addition, Nanjing is a national comprehensive transportation hub, with the density of highway networks and expressways ranking first among the country's central cities. Its railways connect North China, East China, and Central China, and Nanjing is an important junction of the north-south and east-west trunk lines in the four vertical and four horizontal railway patterns. As a result, Nanjing's tourism market has been thriving. By the end of 2018, the total number of tourists received reached 121.8594 million and the total tourism revenue was 246.02 billion yuan, up $7.05 \%$ and $13.43 \%$, respectively, from the previous year. In short, Nanjing is a city with great potential for economic and tourism development in China. Therefore, this paper takes Nanjing as an example to provide a reference for the development of tourism in other cities.

3.2. Index System Construction. The urban tourism environment quality and the tourism economic systems are not simply in a single linear relationship, but a relatively complex one. Thus, this paper adopts the multi-index evaluation method and combines the existing evaluation index system [49-56] and follows the principles of science, integrity, representation, data availability, and operability. We comprehensively considered the evaluation indicators for the coupling coordination of Nanjing's tourism environment quality and tourism economy. Finally, we formulated a synthesis evaluation index system composed of two levels, six aspects, and 25 indicators. Among them, the tourism environmental quality system includes three firstclass indicators: ecological environment, infrastructure, and traffic environment; the tourism economic system includes three first-class indicators: tourism benefit, tourism scale, and tourism status. In the tourism environmental quality system, the ecological environment reflects urban afforestation quality and environmental pollution harnessing effect, tourism infrastructure reveals the overall situation of the city's tourism facilities, and the traffic environment indicates the capacity of a city's traffic. In the tourism economic system, tourism benefits represent the economic benefits 
generated by tourism, tourism scale implies the reception capacity of tourism, and tourism status reflects the status of tourism in relevant cities. The explanations for each indicator are shown in Table 1.

3.3. Data Collection and Preprocessing. To guarantee the availability and continuity of data, this paper selects 25 indicators of the urban tourism environment quality system and the tourism economic system to evaluate the data from Jiangsu Statistical Yearbook and Nanjing Statistical Yearbook from 2009 to 2018 .

3.3.1. Data Standardization. Because each index has different properties and dimensions, formulas (1) and (2) were applied to carry out dimensionless treatment on each index [57]. The formula is as follows:

For positive indicators:

$$
X_{i j}^{\prime}=\frac{X_{i j}-{ }_{i}^{\min }\left(X_{i j}\right)}{{ }_{i} \max \left(X_{i j}\right)-{ }_{i} \min \left(X_{i j}\right)} .
$$

For negative indicators:

$$
X_{i j}^{\prime}=\frac{{ }_{i}^{\max }\left(X_{i j}\right)-X_{i j}}{{ }_{i} \max \left(X_{i j}\right)-{ }_{i}^{\min }\left(X_{i j}\right)},
$$

where $x_{i j}$ represents the original value of the data; $\max \left(x_{i j}\right)$ and $\min \left(x_{i j}\right)$ are the maximum value and minimum value of the $j$ index, respectively; and $x_{i j}^{\prime}$ is the normalized value.

3.4. Entropy Method. Generally speaking, multiattribute decision-making methods can be divided into two categories: subjective weighting method and objective weighting method. The subjective weighting method has a strong subjective consciousness and is judged by experts according to experience; thus, to a certain extent, it lacks practical reference value. The objective weighting method has high credibility and is formed by the actual data of each index in the evaluation. Therefore, this paper adopts the objective weighting method, i.e., the entropy method [8]. The entropy method is not affected by evaluation data, and the objective index weight is obtained according to the variation of indexes; therefore, it has been applied in various studies $[8,35]$. The specific calculation steps are as follows.

3.4.1. Determination of the Index Weight. The entropy method can objectively reflect the degree of importance and change trend of indexes based on the actual information provided. The calculation formula is as follows.

(a) Calculating the proportion of the indicator:

$$
Y_{i j}=\frac{X_{i j}^{\prime}}{\sum_{i=1}^{m} X_{i j}^{\prime}} .
$$

(b) Calculating the information entropy of the indicator:

$$
E_{j}=\frac{1}{\operatorname{Inm}} \sum_{i=1}^{m} Y_{i j} \operatorname{In} Y_{i j} .
$$

(c) Calculating the weight of the indicator:

$$
V_{j}=\frac{1-E_{j}}{\sum_{j=1}^{n}\left(1-E_{j}\right)},
$$

where $Y_{i j}$ indicates the determination of the proportion of the $j$ index and $E_{j}$ is information entropy. The smaller the $E_{j}$ is, the greater the variation degree of index value will be, the more the information it provides, and the greater the weight is. $V_{j}$ is the weight of index $j$.

\subsubsection{Comprehensive Development Level Evaluation Model.} Linear weighting method was used to measure the comprehensive development level of the urban tourism environment quality system and the tourism economic system. The formula is as follows:

$$
Z_{j}=\sum_{i=1}^{m} V_{j} X_{i j}^{\prime},
$$

where $Z_{i}$ represents the comprehensive benefits of the $i$ system; $V_{j}$ is the weight of the $j$ index, which is obtained from formulas (3)-(5); $x_{i j}^{\prime}$ is obtained from formulas (1) and (2) after standardizing the original data.

3.5. Coupling Coordination Model. Coupling is a concept in physics that relates to the degrees of coupling and coupling coordination. It is mainly used to describe the interaction between different systems and the degree of mutual influence [58]. The coupling degree reflects the degree of mutual influence between systems, while the coupling coordination degree reveals the degree of coordinated development between systems [58-60]. On the basis of previous studies, the coupling degree model of Nanjing's tourism environment quality system and tourism economic system is established:

$$
C=\left[\frac{z_{1} z_{2}}{\left(z_{1}+z_{2} / 2\right)}\right]^{1 / 2},
$$

where $C(0 \leq C \leq 1)$ is the coupling degree between $Z_{1}$ city tourism environment quality system and $Z_{2}$ tourism economic system. When $C=0$, there is no correlation between the urban tourism environment quality system and the tourism economic system. When $C=1$, the urban tourism environment quality system and the tourism economic system are in the best coupling state.

The coupling degree reflects the degree of interaction between systems instead of the level of each system, while the coupling coordination degree can reveal both whether each system has a good level and the interaction between systems. Thus, in order to truly reflect the coupling coordination level between the urban tourism environment quality system and the tourism economic system, the following coupling coordination degree model is established: 
TABLE 1: Evaluation index system of the relationship between urban tourism environment quality and the tourism economy.

\begin{tabular}{|c|c|c|c|c|c|}
\hline Systems & $\begin{array}{l}\text { First-class } \\
\text { indicator }\end{array}$ & Second-class indicator & Unit & Interpretation & Reference \\
\hline \multirow{17}{*}{$\begin{array}{l}\text { Tourism } \\
\text { environment quality } \\
\text { system }\left(Z_{1}\right)\end{array}$} & \multirow{8}{*}{$\begin{array}{c}\text { Ecological } \\
\text { environment }\left(Z_{11}\right)\end{array}$} & Urban greening rate $\left(Z_{111}\right)$ & $\%$ & $\begin{array}{c}\text { Reflecting the urban greening } \\
\text { degree }\end{array}$ & {$[49,50]$} \\
\hline & & Per-capita green area $\left(Z_{112}\right)$ & $\mathrm{m}^{2}$ & $\begin{array}{c}\text { Reflecting the per-capita green } \\
\text { degree }\end{array}$ & {$[50]$} \\
\hline & & $\begin{array}{l}\text { Average annual concentration of } \\
\text { sulfur dioxide }\left(Z_{113}\right)\end{array}$ & $\mathrm{mcg} / \mathrm{m}^{3}$ & $\begin{array}{l}\text { Reflecting the sulfur dioxide } \\
\text { pollution degree in the air }\end{array}$ & {$[12,50]$} \\
\hline & & $\begin{array}{l}\text { Average annual concentration of } \\
\text { nitrogen dioxide }\left(Z_{114}\right)\end{array}$ & $\mathrm{mcg} / \mathrm{m}^{3}$ & $\begin{array}{l}\text { Reflecting the nitrogen dioxide } \\
\text { pollution degree in the air }\end{array}$ & {$[12,50]$} \\
\hline & & $\begin{array}{l}\text { Average annual concentration of } \\
\text { inhalable particulate matter }\left(Z_{115}\right)\end{array}$ & $\mathrm{mcg} / \mathrm{m}^{3}$ & $\begin{array}{c}\text { Reflecting the inhalable } \\
\text { particulate matter pollution } \\
\text { degree in the air }\end{array}$ & {$[50]$} \\
\hline & & $\begin{array}{l}\text { Comprehensive utilization rate of } \\
\text { industrial solid waste }\left(Z_{116}\right)\end{array}$ & $\%$ & $\begin{array}{c}\text { Reflecting the ability to govern } \\
\text { and utilize industrial solid } \\
\text { waste }\end{array}$ & {$[51]$} \\
\hline & & $\begin{array}{l}\text { Harmless treatment rate of } \\
\quad \text { domestic waste }\left(Z_{117}\right)\end{array}$ & $\%$ & $\begin{array}{l}\text { Reflecting the ability for } \\
\text { harmless treatment on } \\
\text { domestic waste }\end{array}$ & {$[51]$} \\
\hline & & Sewage treatment rate $\left(Z_{118}\right)$ & $\%$ & $\begin{array}{c}\text { Reflecting the ability for sewage } \\
\text { treatment }\end{array}$ & {$[51]$} \\
\hline & \multirow{4}{*}{$\begin{array}{l}\text { Tourism } \\
\text { infrastructure } \\
\quad\left(Z_{12}\right)\end{array}$} & $\begin{array}{l}\text { Number of A-level scenic spots } \\
\qquad\left(Z_{121}\right)\end{array}$ & unit & $\begin{array}{l}\text { Reflecting the rich degree of } \\
\text { urban tourism resources }\end{array}$ & {$[14,52-54]$} \\
\hline & & $\begin{array}{l}\text { Number of } 5 \text { A-level scenic spots } \\
\qquad\left(Z_{122}\right)\end{array}$ & unit & $\begin{array}{l}\text { Reflecting the rich degree of } \\
\text { urban tourism resources }\end{array}$ & {$[14,52-54]$} \\
\hline & & Total star-rated hotels $\left(Z_{123}\right)$ & Number & $\begin{array}{l}\text { Reflecting the reception } \\
\text { capacity of star-rated hotels }\end{array}$ & {$[1,8]$} \\
\hline & & Total travel agencies $\left(Z_{124}\right)$ & Number & $\begin{array}{l}\text { Reflecting the service capacity } \\
\text { of travel agencies }\end{array}$ & {$[12,54]$} \\
\hline & \multirow{5}{*}{$\begin{array}{c}\text { Traffic } \\
\text { environment }\left(Z_{13}\right)\end{array}$} & Road passenger volume $\left(Z_{131}\right)$ & $\begin{array}{l}10,000 \\
\text { people }\end{array}$ & $\begin{array}{l}\text { Reflecting the number of } \\
\text { tourists in the road receptions }\end{array}$ & {$[52,55]$} \\
\hline & & Railway passenger volume $\left(Z_{132}\right)$ & $\begin{array}{l}10,000 \\
\text { people }\end{array}$ & $\begin{array}{l}\text { Reflecting the number of } \\
\text { tourists in the railway } \\
\text { receptions }\end{array}$ & {$[52,55]$} \\
\hline & & Air passenger volume $\left(Z_{133}\right)$ & $\begin{array}{l}10,000 \\
\text { people }\end{array}$ & $\begin{array}{l}\text { Reflecting the number of } \\
\text { tourists in the air receptions }\end{array}$ & {$[55]$} \\
\hline & & Vehicle operation number $\left(Z_{134}\right)$ & unit & $\begin{array}{l}\text { Reflecting the scale of vehicle } \\
\text { operations }\end{array}$ & {$[56]$} \\
\hline & & Passenger car volume $\left(Z_{135}\right)$ & unit & $\begin{array}{l}\text { Reflecting the overall service } \\
\text { capacity of passenger vehicle }\end{array}$ & {$[56]$} \\
\hline \multirow{7}{*}{$\begin{array}{l}\text { Tourism economy } \\
\text { system }\left(Z_{2}\right)\end{array}$} & \multirow[t]{2}{*}{$\begin{array}{l}\text { Tourism benefits } \\
\qquad\left(Z_{21}\right)\end{array}$} & $\begin{array}{l}\text { Star-rated hotel operating revenue } \\
\qquad\left(Z_{211}\right) \\
\text { Tourism foreign currency earnings } \\
\left(Z_{212}\right)\end{array}$ & $\begin{array}{l}\text { Million } \\
\text { yuan } \\
10,000 \\
\text { dollars } \\
100\end{array}$ & $\begin{array}{l}\text { Reflecting the economic benefit } \\
\text { of star-rated hotel } \\
\text { Reflecting the tourism benefit } \\
\text { of inbound }\end{array}$ & {$[8,52,55]$} \\
\hline & & Domestic tourism income $\left(Z_{213}\right)$ & $\begin{array}{c}\text { million } \\
\text { yuan }\end{array}$ & $\begin{array}{l}\text { Reflecting the tourism benefit } \\
\text { of domestics }\end{array}$ & {$[8,52,55]$} \\
\hline & \multirow{3}{*}{$\begin{array}{l}\text { Tourism scale } \\
\qquad\left(Z_{22}\right)\end{array}$} & $\begin{array}{l}\text { Number of inbound reception } \\
\qquad\left(Z_{221}\right)\end{array}$ & $\begin{array}{l}10,000 \\
\text { people }\end{array}$ & $\begin{array}{l}\text { Reflecting the scale of inbound } \\
\text { tourism reception }\end{array}$ & {$[8,12]$} \\
\hline & & $\begin{array}{l}\text { Number of domestic tourism } \\
\text { reception }\left(Z_{222}\right)\end{array}$ & $\begin{array}{l}10,000 \\
\text { people }\end{array}$ & $\begin{array}{l}\text { Reflecting the scale of domestic } \\
\text { tourism reception }\end{array}$ & {$[8,12]$} \\
\hline & & $\begin{array}{l}\text { Total number of tourism } \\
\text { receptions }\left(Z_{223}\right)\end{array}$ & $\begin{array}{l}10,000 \\
\text { people }\end{array}$ & $\begin{array}{l}\text { Reflecting the total scale of } \\
\text { tourism market }\end{array}$ & [53] \\
\hline & \multirow{2}{*}{$\begin{array}{l}\text { Tourism status } \\
\qquad\left(Z_{23}\right)\end{array}$} & $\begin{array}{l}\text { Proportion of tourism income in } \\
\text { GDP }\left(Z_{231}\right)\end{array}$ & $\%$ & $\begin{array}{l}\text { Reflecting the important role of } \\
\text { tourism in the national } \\
\text { economy }\end{array}$ & {$[8,56]$} \\
\hline & & $\begin{array}{l}\text { Proportion of tourism income in } \\
\text { the output value of the tertiary } \\
\text { industry }\left(Z_{232}\right)\end{array}$ & $\%$ & $\begin{array}{c}\text { Reflecting the overall } \\
\text { development level of the } \\
\text { tourism industry }\end{array}$ & {$[8,56]$} \\
\hline
\end{tabular}




$$
\begin{aligned}
& D=\sqrt{C \times T}, \\
& T=\alpha z_{1}+\beta z_{2},
\end{aligned}
$$

where $D(0 \leq D \leq 1)$ is the coupling coordination degree between $Z_{1}$ city tourism environment quality system and $Z_{2}$ tourism economic system. The higher the value of $D$, the higher the overall level of tourism environment quality and tourism economic development, and the more harmonious the coupling coordination degree relationship. $T$ is the comprehensive evaluation index of $Z_{1}$ city tourism environment quality system and $Z_{2}$ tourism economic system, which reflects the overall benefits or contributions between the two systems. $\alpha$ and $\beta$ are undetermined coefficients. The tourism environment quality system and tourism economic system are equally important to the development of Nanjing; therefore, $\alpha=\beta=0.5$. In addition, in accordance with previous research, the coupling coordinated development level of tourism environment quality system and tourism economy was divided into 10 levels [60]. Table 2 presents the specific evaluation standard of coupling coordination degree grade.

\section{Results}

4.1. Analysis of the Indicators' Weight. According to formulas (3)-(5), the weight of each index of the tourism environment quality system and the tourism economic system can be calculated (Table 3). As shown in Table 3, the weight of the urban tourism environment quality system is 0.7312 , including ecological environment (0.2357), tourism infrastructure (0.1039), and traffic environment (0.3916), indicating that the traffic environment and ecological environment are the most important factors in the urban tourism environment quality, which is consistent with Deng et al. [5] and Tang's research [46]. The secondary indexes that contribute the most are $\mathrm{SO}_{2}$ average annual concentration $\left(Z_{113}=0.0574\right)$, followed by vehicle operation number $\left(Z_{134}=0.0454\right)$, urban greening rate $\left(Z_{111}=0.0429\right)$, and total star-rated hotels $\left(Z_{123}=0.0405\right)$. Most notably, the $\mathrm{SO}_{2}$ average annual and urban greening rate belong to the ecological environment, and these indicators accounted for $50 \%$ in the ranking top 4 secondary indexes based on contribution, which implies that tourists focus more on the quality of urban ecological environment.

In addition, the weight of the tourism economic system is 0.2689 , including tourism benefits $(0.0989)$, tourism scale (0.0985), and tourism status (0.0715). Among them, the proportion of tourism benefits is $36.8 \%$, which shows that tourism benefit is a powerful driving force to promote the development of tourism economy, and the importance of tourism benefits is greater than tourism scale and tourism status. Furthermore, the secondary indicator contributing the most to tourism benefits is the tourism foreign currency earnings $\left(Z_{212}=0.0365\right)$, star-rated hotel operating revenue $\left(Z_{211}=0.0365\right)$, and domestic tourism income $\left(Z_{213}=0.0305\right)$. Thus, it can be seen that the urban tourism economy income mainly relies on the tourism foreign currency and also indicates that urban tourism is more likely to strengthen international cooperation.
4.2. Analysis of Comprehensive Level of Subsystems. After data trimming and collection, according to formula (6), the comprehensive benefit values of Nanjing's tourism environment quality system and tourism economic system from 2009 to 2020 can be obtained (Figure 2 and Figure 3).

As shown in Figure 2, the comprehensive development level of Nanjing's tourism environment quality system fluctuated sharply from 2009 to 2020 but showed an overall upward trend. Thus, based on the development of these trends, we divide the comprehensive Nanjing's tourism environment quality system into two stages: during 2009 to 2013, the tourism environment quality curve presented a rising trend and reached the highest value in 2013 and displayed a strong decreasing trend from 2013 to 2014 , with a $57.5 \%$ rate of decline. The development of tourism environment quality suffered in 2014, which can be attributed to the increase in emissions of sulfur dioxide and nitrogen dioxide in Nanjing that led to increased smog and serious deterioration in air quality. After 2014, a new upward trend emerged. This shows that the evaluation value of tourism environment quality has a significant improvement on the rise, year by year, from 2014 to 2020 , due to the Nanjing Municipal Government having made great efforts to implement ecological environment protection. In general, the comprehensive evaluation curves of traffic environment and urban tourism environment quality are the most similar, which means that the traffic environment has the most significant impact on the tourism environment quality system. In addition, before 2014, the traffic environment development was more extensive than ecological environment and tourism infrastructure; however, because of the Nanjing Municipal Government's efforts to strengthen the tourism traffic management by regulating nonlicensed vehicles, illegally operated vehicles, and scrapped vehicles, the traffic environment has slowly been developing from 2013 to 2014. Most notably, the comprehensive development of Nanjing's tourism infrastructure was the most stable, showing a slow upward trend, but at a relatively low level.

As shown in Figure 3, during 2009-2020, the comprehensive development level of Nanjing's tourism economic system showed an overall trend of gradual increase, with the exception of few years. Before 2012, the comprehensive evaluation value of tourism economy remained at about $0.12 \sim 0.19$ but dropped sharply in the following year from 0.1822 to 0.1004 . In 2013, affected by the global bird flu epidemic, Nanjing's foreign currency income from tourism dropped significantly, down $11.6 \%$ from the previous year, and the number of inbound tourists decreased more than three times from the previous year, resulting in a drop in the total income from the tourism economy. The tourism economy began to pick up again in 2014 and maintained sustained growth until 2019, reaching the highest value of 0.2189 at this stage. From Figure 3, we also observe that the development of the tourism economy suffered a sharply declining trend from 2019 to 2020, including tourism benefits, tourism scale, and tourism status. This reflected the global outbreak of COVID-19 at the end of 2019 causing a huge loss to the tourism economy, in which tourism foreign currency earnings and domestic tourism income declined 
TABLE 2: Evaluation criteria of coupling coordination degree between urban tourism environment quality and the tourism economy.

\begin{tabular}{lcc}
\hline Evaluation grade & Coupling coordination degree $(D)$ & Description \\
\hline Extreme unbalance & $0<D \leq 0.1$ & The development of the two systems is extremely unbalanced \\
Serious unbalance & $0.1<D \leq 0.2$ & The development of the two systems is seriously unbalanced \\
Moderate unbalance & $0.2<D \leq 0.3$ & The development of the two systems is moderately unbalanced \\
Mild unbalance & $0.3<D \leq 0.4$ & The development of the two systems is mildly unbalanced \\
Slightly unbalance & $0.4<D \leq 0.5$ & The development of the two systems is slightly unbalanced \\
Barely coordination & $0.5<D \leq 0.6$ & The development of the two systems is barely coordinated \\
Primary coordination & $0.6<D \leq 0.7$ & The development of the two systems is primarily coordinated \\
Moderate coordination & $0.7<D \leq 0.8$ & The development of the two systems is moderately coordinated \\
Good coordination & $0.8<D \leq 0.9$ & The development of the two systems is favorably coordinated \\
Superior coordination & $0.9<D \leq 1$ & The development of the two systems is superiorly coordinated \\
\hline
\end{tabular}

TABLE 3: Weights of indexes of the two subsystems.

\begin{tabular}{lccccc}
\hline \multicolumn{3}{c}{ Urban tourism environment quality $\left(Z_{1}=0.7312\right)$} & \multicolumn{2}{c}{ Tourism economy $\left(Z_{2}=0.2689\right)$} \\
$\begin{array}{l}\text { Ecological } \\
\text { environment }\end{array}$ & $\begin{array}{c}\text { Tourism infrastructure } \\
\left(Z_{12}=0.1039\right)\end{array}$ & $\begin{array}{c}\text { Traffic environment } \\
\left(Z_{13}=0.3916\right)\end{array}$ & $\begin{array}{c}\text { Tourism benefits } \\
\left(Z_{21}=0.0989\right)\end{array}$ & $\begin{array}{c}\text { Tourism scale } \\
\left(Z_{22}=0.0985\right)\end{array}$ & $\begin{array}{c}\text { Tourism status } \\
\left(Z_{23}=0.0715\right)\end{array}$ \\
\hline$\left.Z_{111}=0.2357\right)$ & $Z_{121}=0.0216$ & $Z_{131}=0.02452$ & $Z_{211}=0.0319$ & $Z_{221}=0.0409$ & $Z_{231}=0.0350$ \\
$Z_{112}=0.0339$ & $Z_{122}=0.0107$ & $Z_{132}=0.0369$ & $Z_{212}=0.0365$ & $Z_{222}=0.0280$ & $Z_{232}=0.0365$ \\
$Z_{113}=0.0574$ & $Z_{123}=0.0405$ & $Z_{133}=0.0315$ & $Z_{213}=0.0305$ & $Z_{223}=0.0295$ \\
$Z_{114}=0.0280$ & $Z_{124}=0.0311$ & $Z_{134}=0.0454$ & & \\
$Z_{115}=0.0237$ & & $Z_{135}=0.0326$ & & \\
$Z_{116}=0.0117$ & & & & & \\
$Z_{117}=0.0201$ & & & & & \\
$Z_{118}=0.0180$ & & & & \\
\hline
\end{tabular}

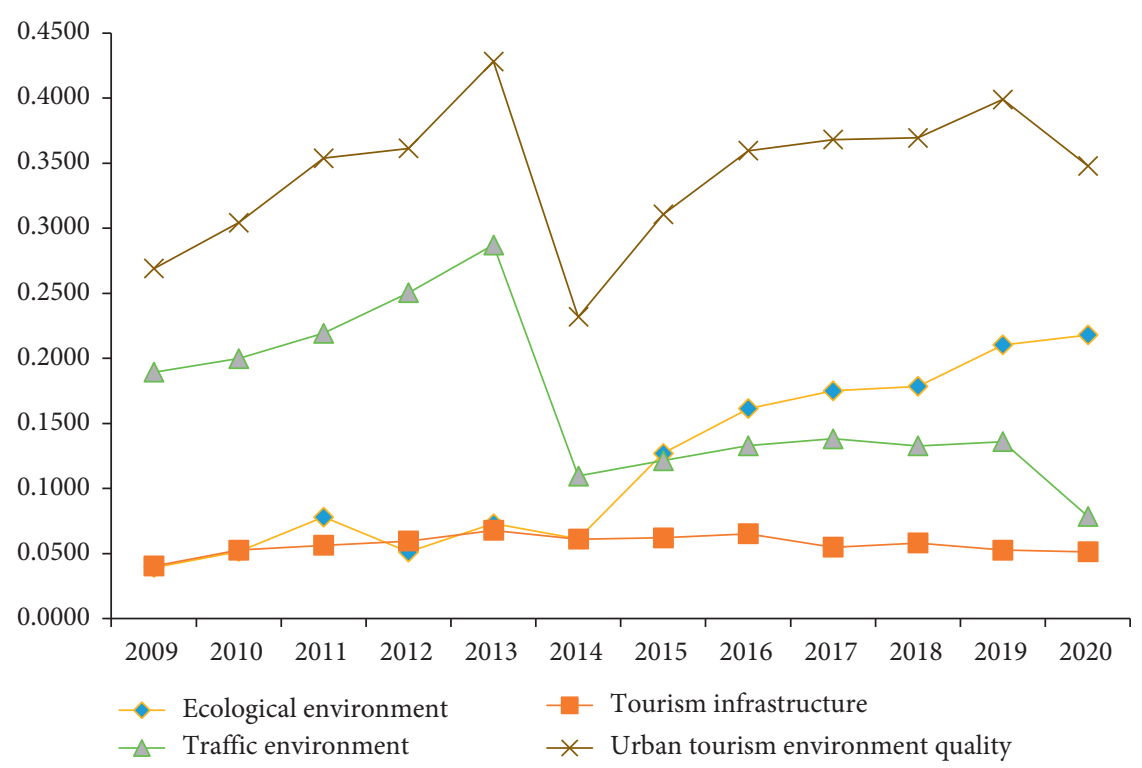

FIGURE 2: Trends of the comprehensive levels in the urban tourism environment.

$59.13 \%$ and $25.54 \%$ over the same period compared with 2019. Meanwhile, Nanjing's tourism status also declined significantly after 2019, and thus tourism revenue only accounted for $19.58 \%$ of the output value of the tertiary industry, dropping 38.83\% compared with 2019. Furthermore, the comprehensive development level of tourism scale and tourism benefits showed a similar trend to the tourism economic system, which indicated that tourism scale and tourism benefits are the most important factors affecting the comprehensive development level of the tourism environment system.

4.3. Analysis of the Degree of Coupling Coordination. Based on the results calculated by formulas (1)-(6) and according to formulas (7) and (8), the coupling coordination 


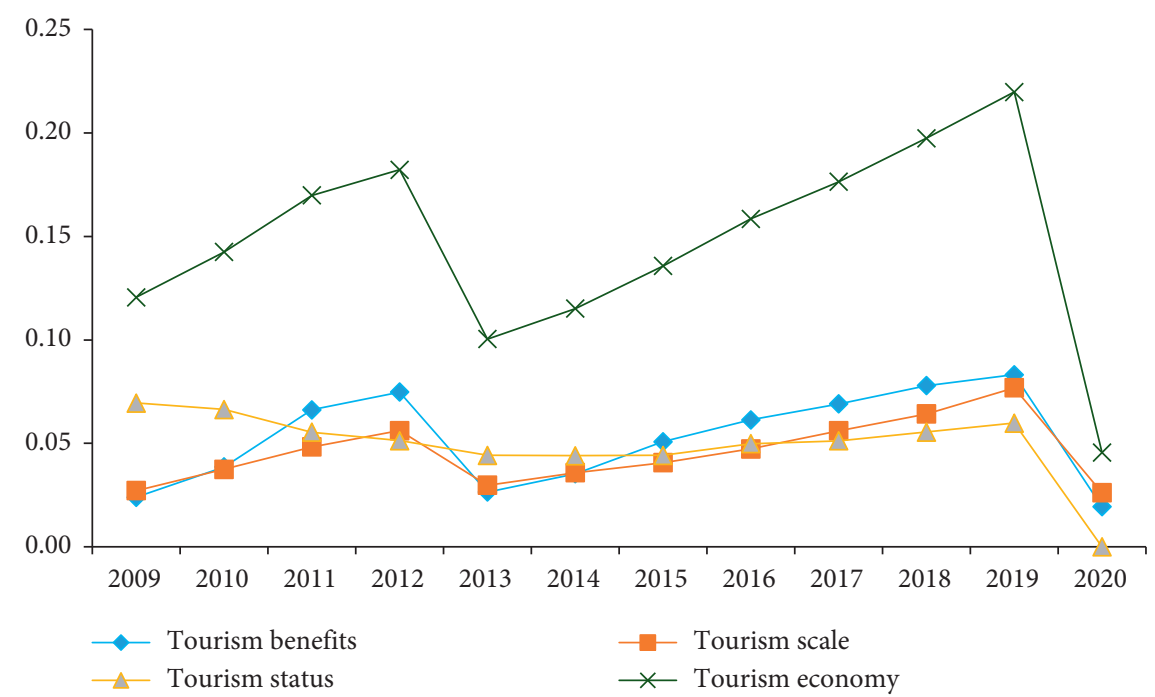

FIgURE 3: Trends of the comprehensive levels in the tourism economy.

degree between Nanjing's tourism environment quality system and the tourism economic system from 2009 to 2020 is obtained (Figure 4), of which the average coupling coordination degree between the two systems is 0.47 , indicating that the two systems are slightly imbalanced development. From Figure 4, it can be seen that the coupling coordination degree curve of the two systems rises slowly at first, then falls, and again go slowly upward and finally rapidly downward, which is mostly consistent with the development curve of tourism environment quality system. Based on the evaluation standard of coupling coordination degree, the coupling coordination level of the two systems is divided into the following three stages.

The first stage (2009-2016) is a slightly imbalanced state. During this stage, the tourism environment quality system and tourism economic system experienced slightly low-level coupling, except in 2012, indicating that the development of the two systems is unbalanced. In 2012, the two systems reached a barely coordinated development trend. This may be due to the two systems interacting more with each other and the improvement of urban tourism environment quality attracting more tourists and creating more tourism income. Because of the global outbreak of bird flu in 2013 causing huge losses to the tourism economy, during 2012-2013, the coupling coordination degree of the two systems dropped from 0.5066 to 0.4553 . However, the tourism environment quality increased significantly over the same period; this was based on the Nanjing Municipal Government's proposal that 2011 is a crucial year for ecological construction and continuous improvement of the quality of the ecological environment. Ecological environmental protection became the focus of work. This fluctuation strongly indicated that the two systems were consistent with a state of low level of coupling coordination during this period. Moreover, the coupling coordination degree curve of the two systems continued to decline to 0.4043 from 2013 to 2014; this lowlevel coupling reflects the serious decline in the quality of Nanjing's tourism environment due to smog, which resulted in imbalance and uncoordinated situation between the two systems. From 2014 to 2016, the level of coupling coordination showed a stable upward trend. The development of urban tourism has always been closely related to the quality of urban ecological environment, which indicates that the two systems are becoming more harmonious.

The second stage (2016-2019) is a barely coordinated state. During this period, the coupling coordination level between the urban tourism environment quality system and the tourism economic system gradually increased, and the coordination degree became higher. Nanjing Municipal Government continued to focus on ecological sustainable development and vigorously promoted the construction of tourism infrastructure and continuously improved transportation facilities. In the construction of tourism infrastructure, the evaluation standards for star-rated scenic spots and star-rated hotels have become more standardized and the number of travel agencies established have also increased year by year. In addition, Nanjing provides a convenient transportation environment, with 2.542 million passenger vehicles in 2019. The high-standard requirements of tourism environment quality result in the provision of better service to tourists, thus attracting more tourists to travel to Nanjing and driving the development of tourism economy. Although the development level of the urban tourism quality system was still higher than that of the tourism economic system, the gap between the two gradually narrowed to 0.1702 by 2019. The coupling coordination degree of the two systems is transitioning from barely coordinated to the edge of primary coordination. It is still far away from high-quality coordination; however, the two systems have established a good interaction relationship.

The third stage (2019-2020) is a mildly imbalanced state. From Figure 4, we observe that the tourism economy experienced a downturn trend, resulting in a decrease in the coupling coordination degree of the two systems. From 2019 to 2020, there was a qualitative change in coupling coordination from barely coordinated to mildly imbalanced. Due to the 


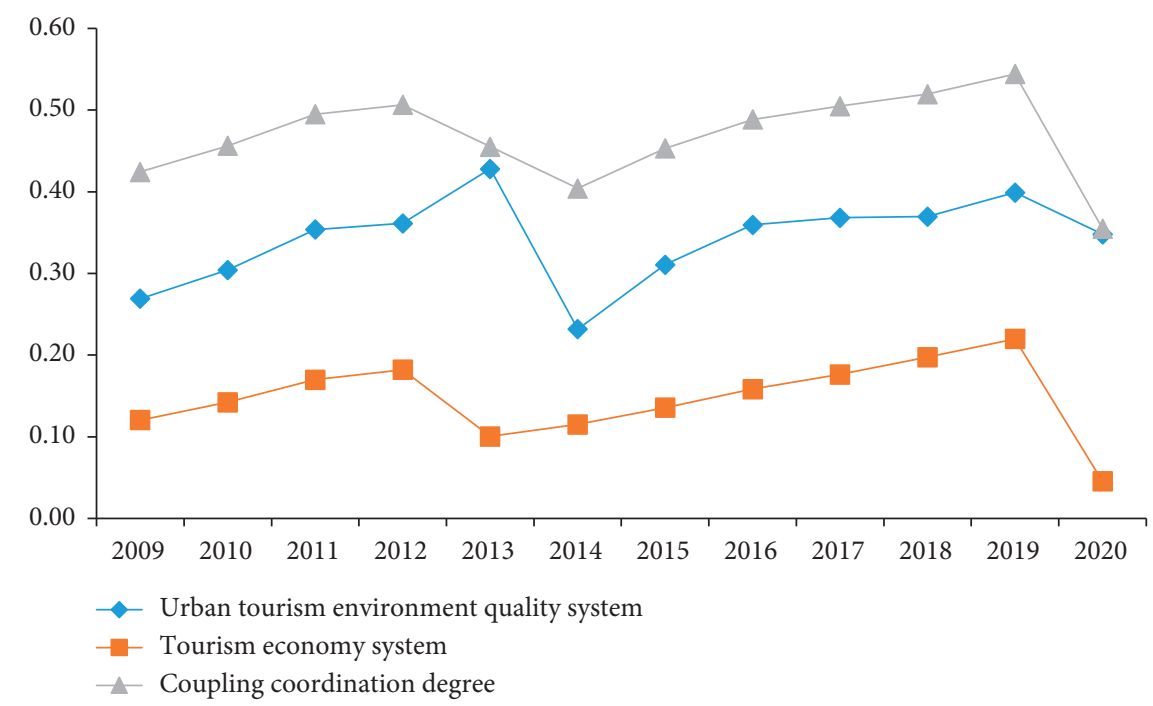

FIGURE 4: Coupling coordination degree of urban tourism environment quality and the tourism economy.

global COVID-19 outbreak, the government encouraged people not to go out unless necessary; this reduced the number of tourists and caused the tourism economy to experience a serious recession. As a result, in 2020, the development of the tourism economy lagged far behind the development of the tourism environment quality, and the overall coupling coordination degree was in a state of disharmony.

\section{Conclusions}

Urban tourism environment quality and tourism economy are important components of sustainable development of urban tourism. Taking Nanjing as an example, this paper constructs a comprehensive evaluation system of urban tourism environment quality and tourism economy and empirically analyzes the coupling coordination level of the two systems by adopting the coupling coordination model. Specifically, our research finds the following: (1) from 2009 to 2020, the comprehensive development level of Nanjing's tourism environment quality system gradually increased, with slight fluctuation. In 2014, due to the increase in emissions of sulfur dioxide and nitrogen dioxide, the development of Nanjing tourism environment quality suffered immensely. After 2014, a new upward trend emerged. Furthermore, the trends in the comprehensive evaluation curves of traffic environment and urban tourism environment quality are the most similar, indicating that the traffic environment has the most significant impact on the tourism environment quality system. (2) Although the comprehensive evaluation value of Nanjing's tourism economy was relatively low from 2009 to 2020, the development of the tourism economy showed an overall uptrend trend, except for a few years. In 2013, Nanjing's foreign currency income from tourism dropped significantly due to the global bird flu epidemic. Similarity, because of the global outbreak of COVID-19 at the end of 2019, the tourism economy system development level was the lowest in 2020. (3) The coupling coordination of tourism environment quality system and tourism economic system is divided into three stages: the slightly imbalanced state from 2009 to 2016, the barely coordinated state from 2016 to 2019 , and the mildly imbalanced state from 2019 to 2020. From 2009 to 2019, the coupling level of the two systems gradually transitioned from a slightly imbalanced state to the primary coordination state. Although the development level of tourism economy still lagged behind that of the tourism environment quality, the coupling coordination degree of the two systems finally changed from imbalance to coordination, and the gap between the two gradually narrowed. However, in 2020, the overall coupling coordination degree experienced a state of disharmony due to the global COVID-19 outbreak.

To sum up, the entropy weight model and coupling coordination model proposed in this paper can objectively and accurately reflect the relationship between urban tourism environment quality and tourism economy and help decision-makers to effectively identify the influencing factors of urban tourism environment quality system and tourism economic system and the relationship between the two. Therefore, in order to rapidly achieve high-quality and coordinated development of the two systems, the following measures are proposed:

(1) Governments should attach importance to urban ecological construction, intensify the publicity related to environmental protection and the supervision of pollutant emissions, implement centralized and classified management of waste, improve the utilization rate of resources, and form a green industrial chain; enterprises need to upgrade outdated operation methods, reduce the discharge of industrial waste gas and wastewater, and establish a green environmental assessment system. Furthermore, the urban greening rate should be constantly improved to create a green and diversified ecological environment.

(2) The management of the tourism transportation industry should be strengthened and direct vehicles for cities and scenic spots should be provided to facilitate people to choose green travel modes; the 
rectification and supervision of the tourism management market need to be intensified to create a good tourism atmosphere; scientific standardization of tourism infrastructure should be carried out to upgrade hardware and software to improve the quality of service and the popularity of tourist attractions.

(3) New technologies should be injected into the economic system to change the economic growth mode, transform the low-end industries in the industrial structure to medium- and high-end industries, and optimize the upgrading of industries; the tertiary industry needs to be actively developed to increase the number of employees and improve people's consumption level; advantages of the tourism environment quality should be fully mobilized, and innovative and feasible operation modes of the tourism industry should be actively explored to improve the efficiency of the tourism industry and increase revenue.

(4) As for responding to public health emergencies, the impact of the epidemic on tourism should be viewed dialectically. On the one hand, we need to fully understand the crisis that epidemics have caused for tourism. On the other hand epidemics are also an opportunity to enhance the governance capacity of the tourism industry. In addition, tourism workers should respond calmly to epidemic crises and turn them into an opportunity for development, because an epidemic is only temporary.

This study also has certain limitations. First, in order to meet the requirements of the research, the tourism environment quality system only involves three aspects: ecological environment, infrastructure, and traffic environment; however, the system is extremely complex and more indicators should be considered to ensure the comprehensiveness of the evaluation. Second, the development structure and tourism industry process of different cities are inconsistent and a spatiotemporal heterogeneity exists; thus, spatial analysis and other new methods can be attempted to study the coupling relationship. Furthermore, a comparative study can be carried out. The comprehensive coupling study of urban tourism environment quality system and tourism economic system proposed in this paper has not been attempted by scholars in other cities in China; as a result, this method cannot yet be used for comparative study. Future research should adopt coupling coordination model to study the relationship between tourism environment quality and tourism economy in more cities at home and abroad.

\section{Data Availability}

To guarantee the availability and continuity of data, this paper selects 25 indicators of urban tourism environment quality system and tourism economic system to evaluate the data from Jiangsu Statistical Yearbook and Nanjing Statistical Yearbook (http://tj.jiangsu.gov.cn/col/col76362/index. html http://tjj.nanjing.gov.cn/bmfw/njtjnj/).

\section{Conflicts of Interest}

The authors declare no conflicts of interest.

\section{Authors' Contributions}

Conceptualization was done by H.M.G; methodology, validation, formal analysis, investigation, resources, and data curation were done by H.M.G and X. G.; original draft preparation was done by H.M.G; review and editing were done by H.M.G and X. G.; supervision was done by H.M.G. All authors have read and agreed to the published version of the manuscript.

\section{References}

[1] F. Higgins-Desbiolles, "Sustainable tourism: sustaining tourism or something more?" Tourism Management Perspectives, vol. 25, pp. 157-160, 2018.

[2] OECD Publishing, World Energy Outlook 2008, Organisation for Economic Co-operation and Development, Paris, France, 2008.

[3] L. Li, Q. Yang, and X. Xie, "Coupling coordinated evolution and forecast of tourism-urbanization-ecological environment: the case study of Chongqing, China," Mathematical Problems in Engineering, vol. 2021, Article ID 7271637, 15 pages, 2021.

[4] Z. M. Tao, "Research on the degree of coupling between the urban public infrastructure system and the urban economic, social, and environmental system: a case study in Beijing, China," Mathematical Problems in Engineering, vol. 2019, Article ID 8206902, 19 pages, 2019.

[5] J. Khadaroo and B. Seetanah, "Transport infrastructure and tourism development," Annals of Tourism Research, vol. 34, no. 4, pp. 1021-1032, 2007.

[6] S. Becken and M. Patterson, "Measuring national carbon dioxide emissions from tourism as a key step towards achieving sustainable tourism," Journal of Sustainable Tourism, vol. 14, no. 4, pp. 323-338, 2006.

[7] S. Perch-Nielsen, A. Sesartic, and M. Stucki, "The greenhouse gas intensity of the tourism sector: the case of Switzerland," Environmental Science \& Policy, vol. 13, no. 2, pp. 131-140, 2010.

[8] Z. Tang, "An integrated approach to evaluating the coupling coordination between tourism and the environment," Tourism Management, vol. 46, pp. 11-19, 2015.

[9] S. A. Alkheder, "Transportation and tourism sustainability in major Jordanian tourism cities," Tourism Planning \& Development, vol. 13, no. 3, pp. 253-273, 2016.

[10] J. O. J. Lundgren, "The tourist Frontier of Nouveau Quebec: functions and regional linkages," Tourist Review, vol. 37, 1982.

[11] B. Ouattara, A. Pérez-Barahona, and E. Strobl, "Dynamic implications of tourism and environmental quality," Journal of Public Economic Theory, vol. 21, no. 2, pp. 241-264, 2019.

[12] Y. Q. Geng, Z. J. Wei, H. Zhang, and M. Maimaituerxun, "Analysis and prediction of the coupling coordination relationship between tourism and air environment: Yangtze River economic zone in China as example," Discrete Dynamics in Nature and Society, vol. 2020, Article ID 1406978, 15 pages, 2020.

[13] D. Lei, W. T. Zhao, Y. L. Huang, S. G. Cheng, and C. Liu, "Research on the coupling coordination relationship between urbanization and the air environment: a case study of the area of Wuhan," Atmosphere, vol. 6, no. 10, pp. 1539-1558, 2015. 
[14] Q. Wang, Z. Mao, L. Xian, and Z. Liang, "A study on the coupling coordination between tourism and the low-carbon city," Asia Pacific Journal of Tourism Research, vol. 24, no. 6, pp. 550-562, 2019.

[15] S. Tan, J. Yang, J. Yan, C. Lee, H. Hashim, and B. Chen, “A holistic low carbon city indicator framework for sustainable development," Applied Energy, vol. 185, pp. 1919-1930, 2017.

[16] B. Prideaux, "Factors affecting bilateral tourism flows," Annals of Tourism Research, vol. 32, no. 3, pp. 780-801, 2005.

[17] C. Massidda and I. Etzo, "The determinants of Italian domestic tourism: a panel data analysis," Tourism Management, vol. 33, no. 3, pp. 603-610, 2012.

[18] D. Badau and A. Badau, "The motric, educational, recreational and satisfaction impact of adventure education activities in the urban tourism environment," Sustainability, vol. 10, no. 6, Article ID 2106, 2018.

[19] L. Zhong, J. Deng, Z. Song, and P. Ding, "Research on environmental impacts of tourism in China: progress and prospect," Journal of Environmental Management, vol. 92, no. 11, pp. 2972-2983, 2011.

[20] C. R. Goeldner and J. B. Ritchie, Tourism Principles, Practices, Philosophies, John Wiley \& Sons, Hoboken, NJ, USA, 2007.

[21] S. R. Paramati, M. Shahbaz, and M. S. Alam, "Does tourism degrade environmental quality? A comparative study of Eastern and Western European Union," Transportation Research Part D: Transport and Environment, vol. 50, pp. 1-13, 2017.

[22] I. Ruiz-Guerra, V. Molina-Moreno, F. J. Cortés-García, and P. Núñez-Cacho, "Prediction of the impact on air quality of the cities receiving cruise tourism: the case of the Port of Barcelona,” Heliyon, vol. 5, no. 3, Article ID e01280, 2019.

[23] B. Zhou, H. Qu, X. Du, B. Yang, and F. Liu, "Air quality and inbound tourism in China," Tourism Analysis, vol. 23, no. 1, pp. 159-164, 2018.

[24] A. Sghaier, A. Guizani, S. Ben Jabeur, and M. Nurunnabi, "Tourism development, energy consumption and environmental quality in Tunisia, Egypt and Morocco: a trivariate analysis," Geojournal, vol. 84, no. 3, pp. 593-609, 2019.

[25] E. Akbostancı, S. Türüt-Aşık, and G. İ. Tunç, “The relationship between income and environment in Turkey: is there an environmental Kuznets curve?" Energy Policy, vol. 37, no. 3, pp. 861-867, 2009.

[26] M. Shahbaz, R. Sbia, H. Hamdi, and I. Ozturk, "Economic growth, electricity consumption, urbanization and environmental degradation relationship in United Arab Emirates," Ecological Indicators, vol. 45, pp. 622-631, 2014.

[27] J. E. Mbaiwa, "The socio-economic and environmental impacts of tourism development on the Okavango Delta, northwestern Botswana," Journal of Arid Environments, vol. 54, no. 2, pp. 447-467, 2003.

[28] S. Gössling, C. B. Hansson, O. Hörstmeier, and S. Saggel, "Ecological footprint analysis as a tool to assess tourism sustainability," Ecological Economics, vol. 43, no. 2-3, pp. 199-211, 2002.

[29] Q. Wang, X. Yuan, C. Ma, Z. Zhang, and J. Zuo, "Research on the impact assessment of urbanization on air environment with urban environmental entropy model: a case study," Stochastic Environmental Research and Risk Assessment, vol. 26, no. 3, pp. 443-450, 2012.

[30] R. Chen, X. Wang, X. Meng et al., "Communicating air pollution-related health risks to the public: an application of the Air Quality Health Index in Shanghai, China," Environment International, vol. 51, pp. 168-173, 2013.
[31] T.-Y. Xia, J.-Y. Wang, K. Song, and L.-J. Da, "Variations in air quality during rapid urbanization in Shanghai, China," Landscape and Ecological Engineering, vol. 10, no. 1, pp. 181-190, 2014.

[32] Y. Luo, H. Chen, Q. Zhu et al., "Relationship between air pollutants and economic development of the provincial capital cities in China during the past decade," PLoS One, vol. 9, no. 8, Article ID e104013, 2014.

[33] S. Gössling, "Global environmental consequences of tourism," Global Environmental Change, vol. 12, no. 4, pp. 283-302, 2002.

[34] W. R. Black, "Sustainable mobility and its implications for tourism," in Tourism and Transport, pp. 57-68, Routledge, Oxfordshire, UK, 2004.

[35] S. Gössling, D. Scott, and C. M. Hall, "Inter-market variability in $\mathrm{CO} 2$ emission-intensities in tourism: implications for destination marketing and carbon management," Tourism Management, vol. 46, pp. 203-212, 2015.

[36] J. W. Lee and T. Brahmasrene, "Investigating the influence of tourism on economic growth and carbon emissions: evidence from panel analysis of the European Union," Tourism Management, vol. 38, pp. 69-76, 2013.

[37] S. R. Paramati, M. S. Alam, and C.-F. Chen, "The effects of tourism on economic growth and $\mathrm{CO} 2$ emissions: a comparison between developed and developing economies," Journal of Travel Research, vol. 56, no. 6, pp. 712-724, 2017.

[38] J. Zha, L. He, Y. Liu, and Y. Shao, "Evaluation on development efficiency of low-carbon tourism economy: a case study of Hubei Province, China," Socio-Economic Planning Sciences, vol. 66, pp. 47-57, 2019.

[39] C. Bi and J. Zeng, "Nonlinear and spatial effects of tourism on carbon emissions in China: a spatial econometric approach," International Journal of Environmental Research and Public Health, vol. 16, no. 18, Article ID 3353, 2019.

[40] A. P. Kirilenko and S. Stepchenkova, "Tourism research from its inception to present day: subject area, geography, and gender distributions," PLoS One, vol. 13, no. 11, Article ID e0206820, 2018.

[41] W. Wang, J. Qiao, J. Cheng, Y. Sun, and W. He, "Research on the impact of economic development of tourism industry based on low carbon mode," International Journal of Low Carbon Technologies, vol. 14, no. 2, pp. 241-246, 2019.

[42] Y. F. Ma, C. H. Zhang, J. S. Liu, Y. Gao, and W. Pang, "Coupling with tourism: a new approach to sustainable development research," Tourism and Hospitality Prospects, vol. 2, no. 3, pp. 1-19, 2018.

[43] D. Guan, W. Gao, W. Su, H. Li, and K. Hokao, "Modeling and dynamic assessment of urban economy-resource-environment system with a coupled system dynamics-geographic information system model," Ecological Indicators, vol. 11, no. 5, pp. 1333-1344, 2011.

[44] C. Fang, H. Liu, and G. Li, "International progress and evaluation on interactive coupling effects between urbanization and the eco-environment," Journal of Geographical Sciences, vol. 26, no. 8, pp. 1081-1116, 2016.

[45] S. Dong, J. Zheng, Y. Li et al., "Quantitative analysis of the coupling coordination degree between urbanization and ecoenvironment in Mongolia," Chinese Geographical Science, vol. 29, no. 5, pp. 861-871, 2019.

[46] F. Deng, Y. Fang, L. Xu, and Z. Li, “Tourism, transportation and low-carbon city system coupling coordination degree: a case study in Chongqing Municipality, China," International Journal of Environmental Research and Public Health, vol. 17, no. 3, Article ID 792, 2020. 
[47] Q. Wu, "Analysis of the coupling mechanism between industrial clusters and regional economic development," Management World, vol. 5, no. 2, pp. 133-134, 2004, in Chinese.

[48] Y. Zhang, J. H. Chen, and Y. Xiong, "A study on the coordination and coordination of tourism development and urban construction: a case study of southeast miao and dong autonomous prefecture in Guizhou," Guizhou Ethnic Studies, vol. 34, no. 5, pp. 155-158, 2013, in Chinese.

[49] C. L. Fu, X. P. Zhang, Z. B. Zhang, and S. F. Gao, "Coupling relationship between Huangshan's tourism industry and lowcarbon city," Resources \& Industries, vol. 19, pp. 1-9, 2017.

[50] T. Zhang and L. Li, "Research on temporal and spatial variations in the degree of coupling coordination of tourismurbanization-ecological environment: a case study of Heilongjiang, China," Environment, Development and Sustainability, vol. 23, no. 6, pp. 8474-8491, 2021.

[51] Q. Cheng, B. Su, and J. Tan, "Developing an evaluation index system for low-carbon tourist attractions in China-a case study examining the Xixi wetland," Tourism Management, vol. 36, pp. 314-320, 2013.

[52] Z. M. Peng and Q. Q. Wu, "Regional differences and spatial pattern evolution of the integration of China's transportation and tourism industries," Journal of Technology Economics, vol. 36, no. 12, pp. 63-71, 2017, in Chinese.

[53] Y. Zhu, Q. Zhu, and Z. Zhu, "Modeling, evaluation and analysis of tourism destination competitiveness: a case study of the Yangtze river Delta of China," Asia Pacific Journal of Tourism Research, vol. 19, no. 8, pp. 932-949, 2014.

[54] J.-H. Huang and K.-H. Peng, "Fuzzy Rasch model in TOPSIS: a new approach for generating fuzzy numbers to assess the competitiveness of the tourism industries in Asian countries," Tourism Management, vol. 33, no. 2, pp. 456-465, 2012.

[55] Q. Zheng, Y. Kuang, and N. Huang, "Coordinated development between urban tourism economy and transport in the pearl River Delta, China," Sustainability, vol. 8, no. 12, Article ID 1338, 2016.

[56] Y. Ma, L. X. Li, and J. R, “Coordination development research among the tourism economy-traffic condition-ecological environment in Shengnongjia Forest District," Economic Geography, vol. 37, no. 10, pp. 215-227, 2017, in Chinese.

[57] H. Zhang, C.-L. Gu, L.-W. Gu, and Y. Zhang, "The evaluation of tourism destination competitiveness by TOPSIS \& information entropy-a case in the Yangtze River Delta of China," Tourism Management, vol. 32, no. 2, pp. 443-451, 2011.

[58] Y. Li, Y. Li, Y. Zhou, Y. Shi, and X. Zhu, "Investigation of a coupling model of coordination between urbanization and the environment," Journal of Environmental Management, vol. 98, pp. 127-133, 2012.

[59] L. Xing, M. Xue, and M. Hu, "Dynamic simulation and assessment of the coupling coordination degree of the economyresource-environment system: case of Wuhan City in China," Journal of Environmental Management, vol. 230, pp. 474-487, 2019.

[60] Y. Sun and Y. Cui, "Evaluating the coordinated development of economic, social and environmental benefits of urban public transportation infrastructure: case study of four Chinese autonomous municipalities," Transport Policy, vol. 66, pp. 116-126, 2018. 